\title{
RISE Editorial
}

\section{Deborah Corrigan}

Published online: 13 January 2013

(C) Springer Science+Business Media Dordrecht 2013

As the new editor of Research in Science Education (RISE), the first thing I would like to do is express my sincere thanks to Stephen Ritchie who has done such an excellent job as editor over the past 5 years. During this time, RISE has grown in stature as a journal to become one of the best in the area of science education research. Thanks must also go to Donna King for her excellent work as Assistant Editor.

I would like to reiterate the aim and scope of the journal outlined in the preface of every issue. RISE publishes scholarly science education research of interest to a wide group of people. Within this statement, I think it is important to highlight what is meant by scholarly, research, and of interest.

In publishing scholarly articles, RISE is looking for articulation of the principles and practices used by scholars to make valid claims about the world and their critique of such claims. Of course, publishing such work is important as it makes these principles and practices known to the scholarly community so that they can be considered, debated, judged, and accepted, rejected or reframed. Importantly, these principles and practices must be constantly advancing in ways that allow our knowledge to advance within the field. So, in looking for works to publish, RISE will seek articles that advance our knowledge in science education research rather than reproducing what we already know.

Research can take many forms, quantitative, qualitative, and mixed methods to name a few. RISE is interested in producing valid and trustworthy research that takes on a variety of forms and embraces new capabilities at hand, particularly around new technologies. Innovative practices and how these relate to science education will be at the forefront of our thinking in RISE.

Scholarly works of interest need to encompass the wide diversity of readership. RISE is the journal associated with the Australasian Science Education Research Association (ASERA), one of the oldest such associations in the world. With ASERA's history from a colonial western tradition, combined with its location within the highly productive and exciting Asian region, the membership of ASERA and the readership of RISE span the

D. Corrigan ( $\square)$

Faculty of Education, Centre for Science, Mathematics and Technology Education, Monash University, Clayton 3800, Australia

e-mail: debbie.corrigan@monash.edu 
globe and cultural perspectives. Hence, the scholarly works of interest published within RISE need to reflect this diversity.

Additionally though they must include a diversity of form. So, RISE will continue to review articles, editorials, book reviews, and other material deemed appropriate by the editors.

I would like to take this opportunity to also thank the Associate Editors, Amanda Berry, Lyn Carter, Brian Hand, and David Palmer, who have all agreed to continue in these positions. 